\title{
New atypical antipsychotics for schizophrenia: iloperidone
}

This article was published in the following Dove Press journal:

Drug Design, Development and Therapy

12 February 2010

Number of times this article has been viewed

\author{
Silvio Caccia' \\ Luca Pasina ${ }^{2}$ \\ Alessandro Nobili \\ 'Laboratory of Drug Metabolism, \\ "Mario Negri" Institute for \\ Pharmacological Research, Milan, \\ Italy; ${ }^{2}$ Laboratory of Quality \\ Assessment of Geriatric Therapies \\ and Services, "Mario Negri" \\ Institute for Pharmacological \\ Research, Milan, Italy
}

\begin{abstract}
The optimal treatment of schizophrenia poses a challenge to develop more effective treatments and safer drugs, to overcome poor compliance, discontinuation and frequent switching with available antipsychotics. Iloperidone is a new dopamine type 2 /serotonin type $2 \mathrm{~A}\left(\mathrm{D}_{2} / 5-\mathrm{HT}_{2 \mathrm{~A}}\right)$ antagonist structurally related to risperidone, expected to give better efficacy with less extrapyramidal symptoms than $\mathrm{D}_{2}$ receptor antagonist antipsychotics. In double-blind phase III trials iloperidone reduced the symptoms of schizophrenia at oral doses from 12 to $24 \mathrm{mg}$. It was more effective than placebo in reducing positive and negative syndrome total score and Brief Psychiatric Rating scale scores; it was as effective as haloperidol and risperidone in post-hoc analysis. Its long-term efficacy was equivalent to that of haloperidol. The most common adverse events were dizziness, dry mouth, dyspepsia and somnolence, with few extrapyramidal symptoms and metabolic changes in short- and long-term studies in adults. Akathisia was rare, but prolongation of the corrected QT (QTc) interval was comparable to haloperidol and ziprasidone, which is of particular concern. Further comparative studies are needed to clarify the benefit/risk profile of iloperidone and its role in the treatment of schizophrenia.
\end{abstract}

Keywords: iloperidone, pharmacology, pharmacokinetics, efficacy, safety

\section{Introduction}

Schizophrenia is a severely debilitating psychiatric disorder observed worldwide, with a median lifetime prevalence of $0.7 \%-1.0 \% .^{1}$ It causes recurring and progressive episodes of positive and negative symptoms, disturbed cognitive function and other abnormalities. $^{2,3}$ This disorder is associated with an increased risk of mortality ${ }^{3}$ and imposes a huge financial burden on society, ${ }^{4}$ although with striking differences in the annual cost of care per patient between and within different countries. ${ }^{5}$ Optimal treatment of the disease could lessen this burden ${ }^{6}$ but it is still challenging to develop effective, safe antipsychotic drugs. Although many antipsychotics are currently available, the treatment response varies widely. Moreover, predicting the response is still hampered by many methodological and clinical problems and is not possible for clinicians in their prescribing practice. ${ }^{7}$

The Clinical Antipsychotic Trials of Intervention Effectiveness (CATIE) showed that antipsychotic treatment was marked by poor compliance, drug discontinuation and frequent switching attributable to lack of efficacy and intolerance in patients with chronic schizophrenia; this was true for the older, conventional antipsychotics (commonly defined as "first-generation" antipsychotics) as well as the secondgeneration drugs introduced in recent years, the so-called "atypical antipsychotics". 8
Correspondence: Silvio Caccia Laboratory of Drug Metabolism, "Mario Negri" Institute for Pharmacological Research, via La Masa, 19;20I56, Milan, Italy Email silvio.caccia@marionegri.it 
Conventional antipsychotics such the well-known phenothiazines (eg, chlorpromazine), butyrophenones (eg, haloperidol) and diphenylbutylpiperidine derivatives (eg, pimozide) are used as first-line therapy for schizophrenia although this is changing and second-generation drugs, introduced after the archetype clozapine, are now the mainstay of treatment in several countries. As a general rule first-generation agents are antagonists at the dopamine type 2 $\left(D_{2}\right)$ receptors and their clinical efficacy is strongly correlated between with their binding affinities for the receptor subtype. ${ }^{9}$ The dopaminergic theory holds that this is possibly because the disease is due to alterations in central dopaminergic transmission, with increased dopamine transmission in the mesolimbic pathway leading to positive symptoms, and reduced dopamine transmission in the mesocortical pathway explaining negative symptoms.

Although the neurochemical origins of schizophrenia do not necessarily lie in this dopamine dysregulation, this is the final common pathway underlying positive psychotic symptoms and may also play a role in negative and cognitive symptoms. ${ }^{10}$ Accordingly, the blockade of dopamine receptors in the mesolimbic pathway by these antipsychotics controls positive symptoms in a substantial proportion of patients. ${ }^{11}$ However, these drugs offer little benefit in controlling negative symptoms or cognitive deficits, and can result in extrapyramidal symptoms (EPS) and a progressively increasing risk of tardive dyskinesia. ${ }^{12,13}$ Prolactin elevation, which can lead to sexual side effects, is also a frequent adverse reaction to these drugs, and occurs with some second-generation antipsychotics too. ${ }^{14}$

Besides being dopamine receptor antagonists, secondgeneration antipsychotics have an additional range of binding activity at various other receptor sites. While each drug has its own receptor profile, most of them show higher affinity for serotonin type $2 \mathrm{~A}\left(5-\mathrm{HT}_{2 \mathrm{~A}}\right)$ than $\mathrm{D}_{2}$ receptors (exceptions are the dopamine- $\mathrm{D}_{2}$ and $-\mathrm{D}_{3}$ receptor antagonist amisulpride and the partial dopamine agonist, or mixed agonist-antagonist at cerebral $\mathrm{D}_{2}$ receptors aripiprazole); this ratio of affinities has been suggested to account for their enhanced efficacy and lower rates of EPS. ${ }^{15,16}$ The blockade of 5- $\mathrm{HT}_{2 \mathrm{~A}}$ receptors may partly reduce the blockade of dopamine transmission. Fewer EPS and lower risk of tardive dyskinesia would result from the reversed $\mathrm{D}_{2}$ blockade in the striatum, although the CATIE study found that there is still 4\%-8\% EPS even with these newer agents. ${ }^{8} 12$ Antagonism at $5-\mathrm{HT}_{2 \mathrm{~A}}$ receptors in the mesocortical pathway and the consequent increase in dopamine transmission in the prefrontal cortex has also been suggested to account for the efficacy against negative symptoms. ${ }^{15}$
However, like first-generation antipsychotics, these newer agents are not free of side effects such as weight gain, hyperglycemia and dyslipidemia; drug-related cardiac changes (QTc prolongation) have also been reported. ${ }^{12}$ This and the above limitations ${ }^{8}$ have prompted a continuing effort to develop more effective and safer antipsychotics that could improve outcomes for schizophrenic patients. Whereas some of these "newer" antipsychotics are still in the premarketing stage, ${ }^{17}$ others have already joined the second-generation therapies. This latter group includes the mixed $\mathrm{D}_{2} / 5-\mathrm{HT}_{2}$ antagonist iloperidone whose efficacy in the treatment of schizophrenia, reassuring metabolic and safety profiles have been established in double-blind placebo-controlled clinical trials. ${ }^{18,19}$ This review analyzes the pharmacological profile, clinical efficacy and tolerability of this new antipsychotic in adults with schizophrenia.

\section{Data sources and selection of studies}

Using the keywords iloperidone, and schizophrenia a literature search was undertaken, using the international database PubMed, to find all the studies published in English. No date constraints were utilized. Data were also collected from the product labelling available at http://www.fanapt. com (accessed on September 2009). A query iloperidone on http://www.clinicaltrials.gov and http://fda.gov did not produce any other completed clinical studies. From PubMed we identified 33 records that matched the two key-words: four were phase III clinical trials and three pharmacogenetic studies.

\section{Pharmacological profile}

Chemically, iloperidone (HP 873; ILO-522; 1-[4-[3-[4(6-fluoro-1,2-benzisoxazol-3-yl)-1-piperidinyl]propoxy]3-methoxyphenyl]ethanone) is a piperidinyl-benzisoxazole derivative structurally related to risperidone (see Figure 1), the first of the post-clozapine antipsychotics to become widely available. It was selected from a large series of piperidinyl-benzisoxazoles because it showed 300-times more potency in a test for limbic activity (inhibition of apomorphine-induced climbing) than in a test for nigrostriatal activity (inhibition of apomorphine-induced stereotypy). The large difference of potency in these tests was expected to result in a better ratio of therapeutic effect to EPS liability compared with standard antipsychotics. ${ }^{20}$ In a similar chemical class are ziprasidone and other benzisothiazole derivatives with antipsychotic activity. Besides the chemical 


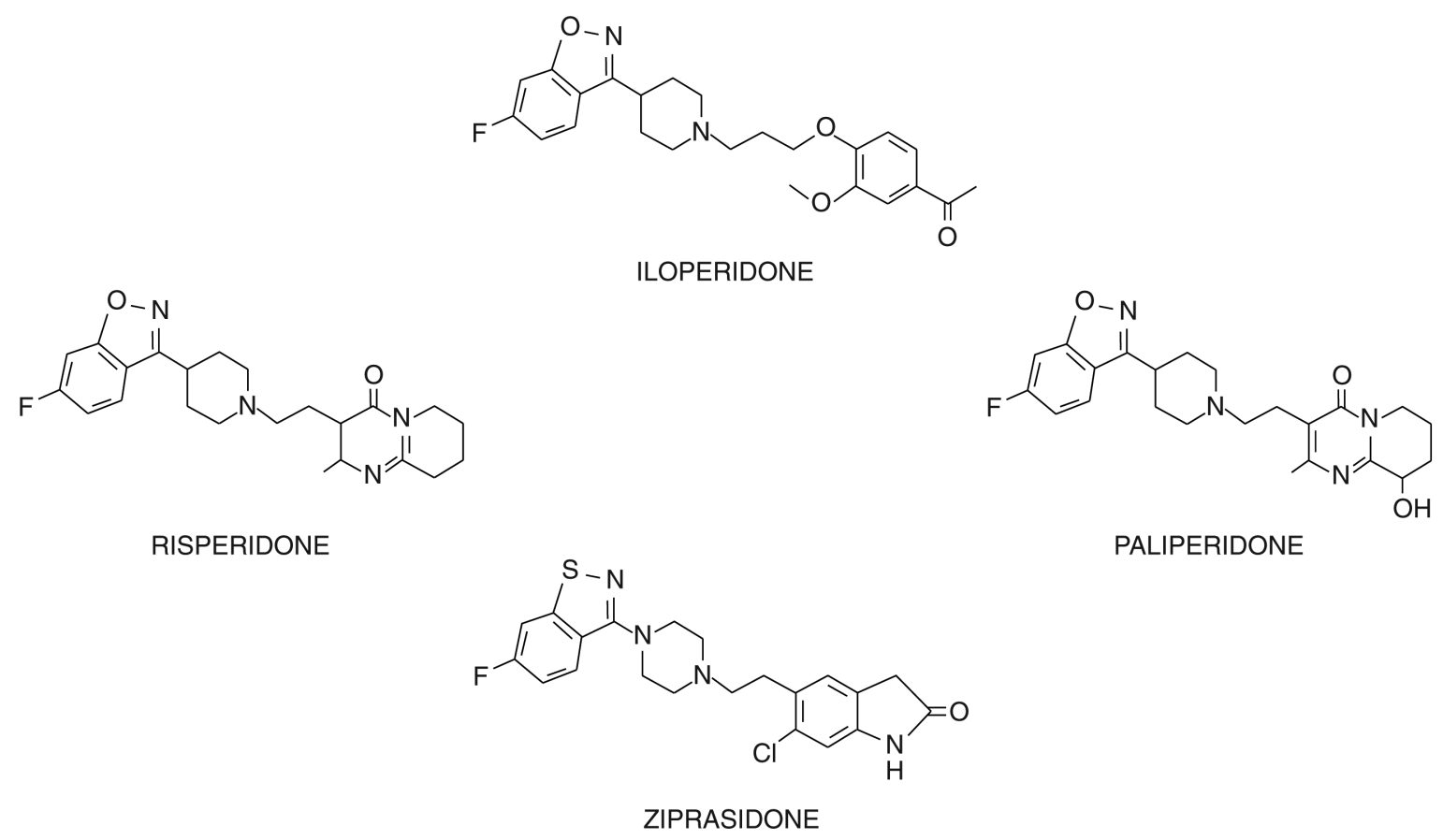

Figure I Chemical structures of iloperidone, risperidone, paliperidone (9-hydroxyrisperidone) and ziprasidone.

structure, benzisothiazoles and benzisoxazoles share some minor metabolic pathways. ${ }^{21}$

Like risperidone, ziprasidone, and other atypical antipsychotics, iloperidone adheres to the $5-\mathrm{HT}_{2 \mathrm{~A}} / \mathrm{D}_{2}$ receptor hypothesis ${ }^{15}$ in that it has higher affinity for the $5-\mathrm{HT}_{2 \mathrm{~A}}$ receptor $\left(\mathrm{K}_{\mathrm{i}}<10 \mathrm{nM}\right)$ than for the $\mathrm{D}_{2}$ receptor $\left.\mathrm{K}_{\mathrm{i}}=10-100 \mathrm{nM}\right) .{ }^{22,23}$ As mentioned, in theory it should have greater efficacy and fewer EPS than first-generation antipsychotic drugs. ${ }^{15}$ Iloperidone, however, is different as it binds to other serotonin receptors. It has moderate affinity for $5-\mathrm{HT}_{1 \mathrm{~A}}, 5-\mathrm{HT}_{2 \mathrm{C}}$, and $5-\mathrm{HT}_{6}\left(\mathrm{~K}_{\mathrm{I}}: 10-100 \mathrm{nM}\right)$, behaving as an antagonist at $5 \mathrm{HT}_{2 \mathrm{C}}$ and $5 \mathrm{HT}_{6}$ receptors, and as a partial agonist at $5 \mathrm{HT}_{1 \mathrm{~A}}$. With other dopamine receptor subtypes, it showed high affinity for the dopamine type 3 receptor and moderate affinity for the dopamine type 4 receptor. ${ }^{22-25}$

In addition to its affinities for serotonin and dopamine receptors, iloperidone has high affinity for alpha ${ }_{1}$ receptors $\left(\mathrm{K}_{\mathrm{i}}<10 \mathrm{nM}\right)$ and moderate affinity for alpha ${ }_{2 \mathrm{C}}$ receptors. Blockade of these receptors may contribute to the drug's efficacy, particularly on mood and cognition, although it may also cause postural dizziness or orthostatic hypotension ${ }^{23,25}$ Blockade of $\alpha_{2 C}$ adrenoceptors might translate into antidepressant and anxiolytic activity. ${ }^{23}$

The affinity for all other receptors was low, including norepinephrine alpha(2A), alpha(2B), beta(1), and beta(2), dopamine $\mathrm{D}(1)$ and $\mathrm{D}(5), \operatorname{CCK}(\mathrm{A})$ and $\mathrm{CCK}(\mathrm{B})$, 5-HT(7), dopamine and norepinephrine transporters.
Interestingly, iloperidone had little affinity for cholinergic muscarinic receptors M1-M5, so it is not likely to have anticholinergic effects. Iloperidone also displayed low affinity for the histamine $\mathrm{H}_{1}$ receptors $^{23}$ and has in fact little effect on body weight (see below), although some other neurotransmitter may be involved in the less severe weight gain potential than with other antipsychotics. ${ }^{26}$

The potential clinical efficacy of iloperidone was also predicted through a series of behavioural studies in animal models. These included the apomorphine-induced climbing mouse paradigm, the 5-HT-induced head twitch and pole climb avoidance in rats and continuous Sidman avoidance responding in monkeys. ${ }^{27}$ Consistent with iloperidone's effect in reversing elevated acoustic startle in both cirazoline-treated and isolation-reared rats, ${ }^{28}$ it had anxiolytic-like properties in the elevated plus maze in rodents and in preclinical assays predictive of efficacy in social interaction..$^{27,29}$ Importantly, it showed only minimal activity in tasks predictive of EPS liability. ${ }^{20,27}$ Findings have been reviewed elsewhere. ${ }^{17,30,31}$

More recently, iloperidone was shown to improve rat choice accuracy in a delayed non-matching-to-position paradigm, suggesting a specific effect on working memory, although measures of task performance did not improve. In comparison, clozapine had no effect on choice accuracy and did not affect non-mnemonic parameters, except for the number of omissions at the higher dose. Haloperidol, on the other hand, impaired most non-mnemonic parameters, 
especially at higher doses, and tended to have a detrimental effect on choice accuracy. ${ }^{32}$

\section{Pharmacokinetics}

Iloperidone is rapidly absorbed reaching peak concentrations between 2 and 5 hours after oral doses in healthy subjects and renally and hepatically impaired patients. ${ }^{33,34}$ It's pharmacokinetics were linear after doses of 3 and $5 \mathrm{mg}$ in healthy subjects. ${ }^{34}$ However, some nonlinearity was seen in schizophrenic patients over the dosage range of 2-12 mg bid, although its main metabolites (see below) had linear pharmacokinetics. ${ }^{34}$ The relative bioavailability of the tablet formulation compared to oral solution was $96 \%$ in healthy subjects. ${ }^{33,34}$

Food (standard breakfast) did not significantly affect the bioavailability of iloperidone in healthy subjects, only slightly delaying its rate of absorption (and the rate of appearance of its main metabolites). ${ }^{35}$ Therefore like most antipsychotics, iloperidone can be administered without regard to meals. However, the administration of ziprasidone with food approximately doubles its absolute availability, and a highcarbohydrate, high-fluid diet almost halves the already low oral bioavailability of amisulpride, although a high-fat meal did not alter its absorption (for review see ${ }^{21}$ ).

Once absorbed, iloperidone rapidly distributes in tissues, as evidenced by the large volume of distribution of 1340-2800 L. ${ }^{33,34}$ Brain uptake is extensive, ${ }^{36}$ like most antipsychotics except substrates of the efflux transporter P-glycoprotein such as risperidone..$^{37}$ Binding to plasma proteins is about $93 \%$ over the concentration range $5-500 \mathrm{ng} / \mathrm{mL}$ (reviewed $\mathrm{in}^{36,38}$ ) and is unchanged by renal impairment (97\%) or hepatic impairment $(97 \%)$. $^{33,34}$

Like most antipsychotics iloperidone undergoes extensive presystemic elimination and is cleared through multiple metabolic pathways mediated by different enzymes (exceptions are amisulpride and paliperidone whose clearance are largely trough urinary excretion; see for reviews ${ }^{21,39}$ ). In a reversible step, the iloperidone acetophenone ring structure (1, in Figure 2 ) is reduced to form reduced iloperidone (P88-8991; 2). ${ }^{40,41}$ Cytosolic enzymes are most likely the primary system by which this occurs, although CYP1A2, CYP2E1 and CYP3A4 may also play a role. ${ }^{41}$ Reduced iloperidone crosses the bloodbrain barrier and shows high affinity for serotonin $5-\mathrm{HT}_{2 \mathrm{~A}}$, adrenergic alpha ${ }_{1}$, alpha ${ }_{2 \mathrm{C}}$ and dopamine $\mathrm{D}_{2}$ receptors, similar to the parent drug, with equal affinity for the alpha ${ }_{2 C}$ and $D_{2}$ receptors. ${ }^{42}$ After a single $3 \mathrm{mg}$ oral dose in CYP2D6 normal metabolizers (EM) and poor metabolizers (PM) it reached plasma $\mathrm{C}_{\max }$ comparable to those of the parent drug. Mean plasma area under the curve (AUC) was higher in PM than in EM but exposure to reduced iloperidone was higher than to iloperidone in both populations, suggesting that the active metabolite is likely to account for a substantial part of the drug's clinical profile (Table 1).

Reduced iloperidone is primarily cleared by glucuronidation, ${ }^{41}$ with elimination half-lives $\left(t_{1 / 2}\right)$ of 25.5 and 37.3 hours respectively in EM and PM, after 3 mg iloperidone orally. ${ }^{34}$ At this dose, in these populations, the elimination $\mathrm{t}_{1 / 2}$ of iloperidone were 17.6 hours and 32.8 hours, ${ }^{34}$ therefore it must be assumed that steady-state concentrations of the active forms are attained within 5-6 days of dosing. Unpublished studies suggest that at steady state reduced iloperidone accounts for $19.5 \%$ and $34 \%$ of total plasma exposure (iloperidone plus metabolites) although results were not detailed..$^{33}$

CYP2D6-mediated oxidation of the ethanone part of the molecule results in the $\alpha$-hydroxy ketone $(4$, in Figure number 2), which is converted (the mechanism is still under investigation $)^{41}$ to the other major circulating metabolite, P95-12113 (Figure number 5), in human plasma. ${ }^{33,34}$ This metabolite has poor in vitro activity at the $5-\mathrm{HT}_{2 \mathrm{~A}}$ and noradrenaline alpha ${ }_{1}$ and alpha ${ }_{2}$ receptors. ${ }^{42}$ It reached higher plasma concentrations in CYP2D6 EM than in CYP2D6 PM after $3 \mathrm{mg}$ iloperidone (Table 1), ${ }^{34}$ representing $48 \%$ of the iloperidone plasma AUC in EM and 25\% in PM at steady state. ${ }^{33}$ However, it does not cross the blood-brain barrier in rodents and therefore it probably only contributes to peripheral side effects of iloperidone. ${ }^{42}$ In contrast, the primarily oxidized metabolite of risperidone, 9-hydroxyrisperidone, which accounts for most of total risperidone exposure, essentially retains the central activity of the parent drug (reviewed $\mathrm{in}^{21,43}$ ) and has been recently approved as the new antipsychotic drug paliperidone.

Other oxidative routes include the CYP3A4-mediated $\mathrm{O}$-demethylation of the acetophenone ring structure (Table 1 number 3). Metabolites are then eliminated through further oxidation and conjugation with glucuronic acid. ${ }^{40,41}$ Excretion is mainly renal, with about $58.2 \%$ and $45.1 \%$ of radioactive iloperidone recovered in urine of EM and PM; feces contribute for $19.9 \%$ (EM) to $22.1 \%$ (PM) of total radioactivity. ${ }^{33}$

\section{Drug interactions}

The importance of CYP2D6 in iloperidone clearance is underlined by its interaction with potent inhibitors of these enzymes (no inducers are known at present). Fluoxetine (20 mg twice daily for 21 days with $3 \mathrm{mg}$ iloperidone to healthy subjects) raised the plasma AUC of iloperidone 


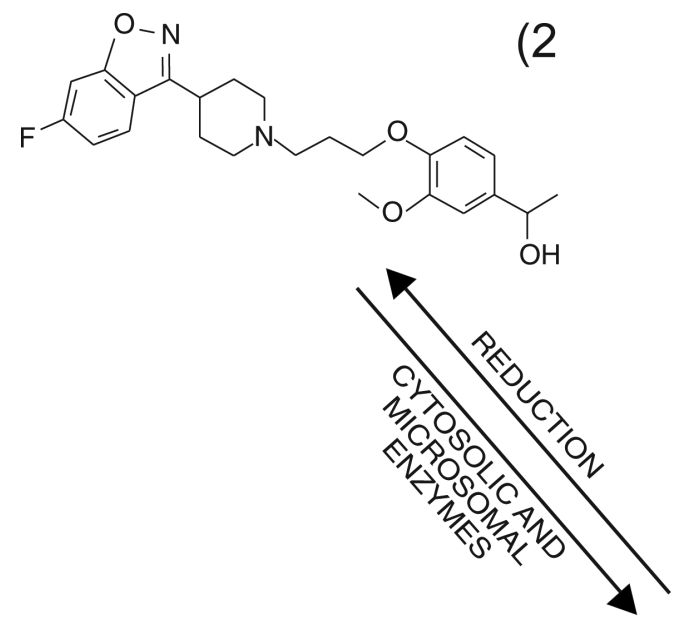<smiles>CC(=O)c1ccc(OCCCN2CCC(c3noc4cc(F)ccc34)CC2)c(O)c1</smiles><smiles>COC(C)=C(C)OCCCN1CCC(c2noc3cc(F)ccc23)CC1</smiles><smiles>COc1cc(C(=O)CO)ccc1OCCCN1CCC(c2noc3cc(F)ccc23)CC1</smiles><smiles>COc1cc(O)ccc1OCCCN1CCC(c2noc3cc(F)ccc23)CC1</smiles>

Figure 2 Main metabolic pathways of iloperidone.

and its reduced form by $137 \%$ and $121 \%$ respectively, and lowered the AUC of its main oxidized metabolite by $53 \%$ when administered. However, iloperidone did not alter the pharmacokinetics of fluoxetine and its active metabolite norfluoxetine..$^{33,34}$

Similarly, co-administration of paroxetine $(20 \mathrm{mg} /$ day for 5-8 days) with multiple doses of iloperidone ( 8 or $12 \mathrm{mg}$ twice daily) to patients with schizophrenia raised mean steadystate peak concentrations of iloperidone and its reduced metabolite about 1.6-fold, and halved mean steady-state peak concentrations of the main inactive metabolite..$^{33,34}$ However, there were no clinically relevant effects on the pharmacokinetics of dextromethorphan $(80 \mathrm{mg}$, a CYP2D6 substrate) when given concomitantly with iloperidone ( $3 \mathrm{mg}$ ) in healthy subjects, suggesting that interactions between iloperidone and other CYP2D6 substrates are unlikely. ${ }^{33}$

Although CYP3A4-mediated O-demethylation is a minor metabolic pathway, with minimal concentrations of 
Table I Exposure to iloperidone and its main metabolites in extensive and poor CYP2D6 metabolizers after single oral doses

\begin{tabular}{|c|c|c|c|c|}
\hline \multirow[t]{3}{*}{ Compound } & \multicolumn{4}{|c|}{ Metabolizers at CYP2D6 } \\
\hline & \multicolumn{2}{|l|}{ EM } & \multicolumn{2}{|l|}{ PM } \\
\hline & $\begin{array}{l}C \max \\
(\mathrm{ng} / \mathrm{mL})\end{array}$ & $\begin{array}{l}\text { AUC } \\
\text { (ng.h/mL) }\end{array}$ & $\begin{array}{l}\text { Cmax } \\
(\mathrm{ng} / \mathrm{mL})\end{array}$ & $\begin{array}{l}\text { AUC } \\
\text { (ng.h/mL) }\end{array}$ \\
\hline Iloperidone & $2.79(27)$ & $29.4(36)$ & $2.26(13)$ & $46.3(17)$ \\
\hline Metabolite $2^{\mathrm{a}}$ & $2.32(30)$ & $49.4(43)$ & $3.33(20)$ & $96.4(21)$ \\
\hline Metabolite $5^{\mathrm{b}}$ & $4.50(34)$ & $153.8(26)$ & $0.67(44)$ & $32.1(36)$ \\
\hline
\end{tabular}

Means with (CV\%); the dose of iloperidone was $3 \mathrm{mg}^{34}$

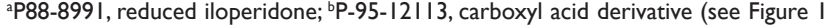
for chemical structure). ${ }^{41}$

Abbreviations: EM, extensive metabolizers; PM, poor metabolizers.

O-desmethyl iloperidone present in human plasma after oral iloperidone, the potent CYP3A4 inhibitor ketoconazole ( $200 \mathrm{mg}$ twice daily for 4 days) raised the AUC of iloperidone ( $3 \mathrm{mg}$ ) by $57 \%$ and that of its active and inactive metabolites by $55 \%$ and $35 \%$, respectively. ${ }^{33,34}$

Importantly, a QTc (corrected QT) prolongation of 9 milliseconds was reported after $12 \mathrm{mg}$ b.i.d iloperidone in patients with schizophrenia or schizoaffective disorder, with an increase in the mean QTc from baseline of about 19 milliseconds when the drug was given concomitantly with paroxetine ( $20 \mathrm{mg} /$ day) and ketoconazole (200 $\mathrm{mg}$ twice daily). Therefore iloperidone doses should be halved when administered with strong inhibitors of CYP2D6 or CYP3A4, in view of the potential for QT interval prolongation subsequent to increased exposure to iloperidone and metabolites. ${ }^{33,34}$

Judging from in vitro studies, iloperidone is not a substrate for other CYP enzymes generally involved in drug metabolism. This suggests it is unlikely to interact with drugs that inhibit or induce these enzymes. ${ }^{33}$ Also, smoking should not affect its pharmacokinetics, like most antipsychotics except the CYP1A2 substrates clozapine and olanzapine whose clearance is affected by cigarette smoking and drugs that induce or inhibit CYP1A2. ${ }^{21}$ In vitro studies in human liver microsomes showed that iloperidone do not induce CYP1A2, CYP2C8, CYP2C9, CYP2C19, CYP3A4 and CYP3A5. ${ }^{33}$

\section{Efficacy}

The efficacy of iloperidone in patients with schizophrenia (DSM-III/IV criteria) has been established in nine integrated clinical studies: two phase II, ${ }^{44,45}$ four pivotal phase III and three long-term efficacy trials..$^{46-50}$

\section{Phase II}

In the first six-week phase II study, 104 hospitalized patients with acute or relapsing schizophrenia were enrolled in a placebo-controlled trial and received a fixed dose of either 4 or $8 \mathrm{mg} /$ day of iloperidone, after titration over 3-10 days. Although both iloperidone groups improved, the $8 \mathrm{mg} /$ day group showed a significant improvement in comparison with placebo, with a mean total score reduction of 18 points of the Positive and Negative Syndrome Scale (PANSS). No other efficacy scores were statistically significant. ${ }^{44,45}$

Another phase II study investigated the maximum tolerated once-daily dose of iloperidone and checked orthostatic blood pressure. Twenty-four out-patients with schizophrenia were enrolled to receive iloperidone at dosages of 2, 4, 6, 8, $12,16,20,28$ and $32 \mathrm{mg}$, with increases every three days, or 1, 2, 4, 8, 12, 16, 20 and $24 \mathrm{mg}$ with dose titration every two days, or the latter dosage range, but with dose titration every day. In each group the highest dosage was continued for four days. Doses of iloperidone up to $32 \mathrm{mg}$ /day were well tolerated. ${ }^{44,46}$

\section{Phase III}

Table 2 summarizes the phase III clinical trials. All eligible patients had a diagnosis of schizophrenia according to Diagnostic and Statistical Manual of Mental Disorders, 4th Edition (DSM-IV) criteria. When specified, exclusion criteria included: history or diagnosis of chemical dependence, recreational drug or alcohol use, toxic psychosis in the last six months, imminent risk of suicide, major neurological deficit, congenital disorder, congenital QT-syndrome, psychotic symptoms that had not improved after adequate treatment with two antipsychotics in the preceding two years. Iloperidone was given orally twice daily with titration according to the manufacturer's prescribing information. Comparator drugs were given at recommended target dosages.

\section{Short-term efficacy}

Three pivotal phase III clinical trials (study 1, study 2, and study 3) evaluated the short-term efficacy of iloperidone. ${ }^{47}$ All were six-week, randomized, double-blind, placebo- and active comparator-controlled trials in patients with acute or subacute exacerbation of schizophrenia or schizoaffective disorders. After pre-randomization screening and a single-blind threeday placebo run-in, patients were randomized to iloperidone (seven-day fixed titration period followed by five weeks of maintenance therapy), active control, or placebo. Patients in study 1 randomly received iloperidone 4,8 and $12 \mathrm{mg}$ /day or haloperidol $15 \mathrm{mg} /$ day, or placebo. The randomization in study 2 was for iloperidone (4 to $8 \mathrm{mg} /$ day or 10 to $16 \mathrm{mg} /$ day), risperidone (6 to $8 \mathrm{mg} /$ day) or placebo. In study 3 , patients were randomized to iloperidone (12 to $16 \mathrm{mg}$ /day 


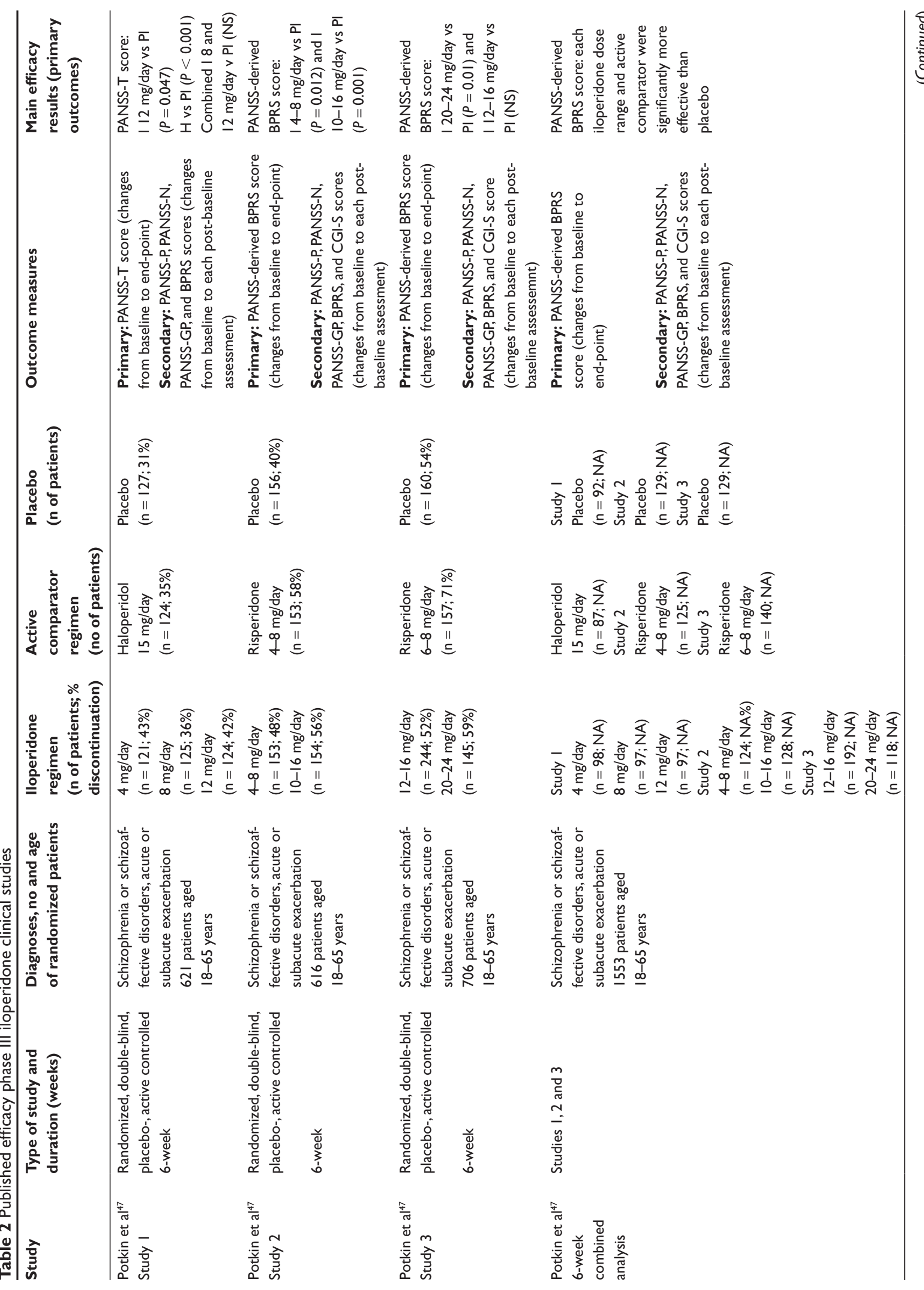




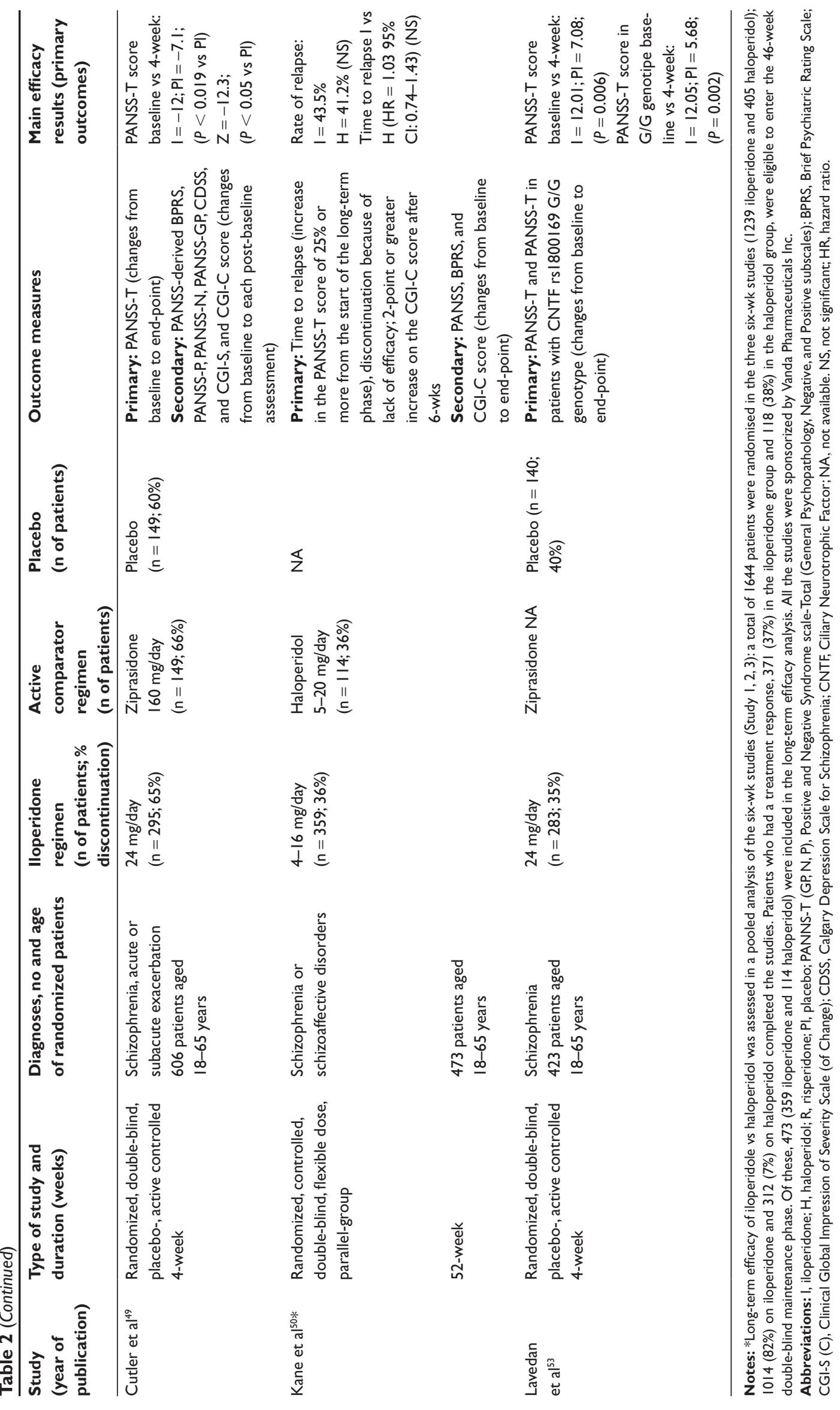


or 20 to $24 \mathrm{mg} /$ day), risperidone (6 to $8 \mathrm{mg} /$ day) or placebo. All drugs were given twice daily. The primary efficacy measure was the change from baseline to end-point in PANSS-total (PANSS-T) scores and in the Brief Psychiatric Rating Scale (BPRS). Results were determined with an intent-to-treat (ITT) population, which included patients who had received at least one dose of the study medication and had at least one complete PANSS assessment, using the last observation carried-forward (LOCF) method.

At least one iloperidone dosing group was significantly more efficacious than placebo in each study. In study 1 , $12 \mathrm{mg} /$ day reduced on the PANSS-T score by 9.9, which was significantly different from the 4.6-point reduction observed with placebo $(P=0.047)$. There were no significant differences between iloperidone $4 \mathrm{mg}$ /day or $8 \mathrm{mg} /$ day and placebo. Patients treated with haloperidol $15 \mathrm{mg} /$ day had a mean reduction of 13.9 points $(P<0.001)$ in the PANSS-T score. In studies 2 and 3 there was significant improvement from baseline in BPRS scores at all iloperidone doses and for risperidone. Compared with placebo these changes were significant for both doses of iloperidone in study 2 , and for iloperidone 20 to $24 \mathrm{mg}$ /day in study 3 . A combined analysis of all eligible patients $(n=1553)$ showed that each dose of iloperidone or active comparator was significantly more effective than placebo.

An additional four-week, phase 3 trial evaluated the efficacy of iloperidone in hospitalized patients with acute psychotic exacerbation of schizophrenia. ${ }^{49} \mathrm{~A}$ total of 593 subjects aged 18-65 years with a baseline PANSS-T score $\geq 70$, a Clinical Global Impression-Severity (CGI-S) score $\geq 4$, and a PANSS positive (PANSS-P) score $\geq 4$ for at least two among delusions, conceptual disorganization, hallucinations, and suspiciousness/persecution, were randomized to receive iloperidone, ziprasidone or placebo. The dosage for active treatment was titrated over the first week (iloperidone 1, 2, $4,6,10$, and $12 \mathrm{mg}$ twice daily titrated sequentially each day on days 1 to 7 ; ziprasidone $20 \mathrm{mg}$ twice daily on days 1 and 2, $40 \mathrm{mg}$ twice daily on days 3 and 4, $60 \mathrm{mg}$ twice daily on days 5 and 6 , and $80 \mathrm{mg}$ twice daily on day 7); placebo was administered twice daily. The study was not designed as a head-to-head comparison between iloperidone and ziprasidone.

Patients in the three groups had similar completion rates (iloperidone 65\%; ziprasidone 66\%; placebo 60\%), and withdrawal of consent was the most frequent reason for early discontinuation, followed by unsatisfactory therapeutic effect and adverse events. There was a significant reduction from baseline to endpoint in PANSS-T scores with iloperidone $(-12.0 ; P=0.006)$ and ziprasidone $(-12.3$; $P=0.012)$ compared with placebo $(-7.1$, which is a low placebo response). Furthermore, iloperidone worked for both the positive and negative clusters of symptoms, and all the secondary rating scales were statistically better with iloperidone than with placebo. Rates of response for ziprasidone were not reported.

In post-hoc analysis of study 3 iloperidone 12-24 and 20-24 mg/day was shown to be equivalent to risperidone 6-8 mg/day. ${ }^{51}$ After six weeks' treatment no significant differences was found in changes from baseline for PANSS-T and BPRS scores. Results were similar comparing iloperidone $12 \mathrm{mg}$ /day with haloperidol $15 \mathrm{mg}$ /day in a post hoc analysis of four six-week studies. ${ }^{52}$

\section{Long-term efficacy}

Long-term efficacy was evaluated in three 52-week prospective, double-blind, randomized non-inferiority studies.$^{50}$ After a six-week stabilization phase, patients entered a 46-week, long-term, double-blind maintenance phase. Of 1644 randomized patients, 1326 completed the stabilization phase: 473 (359 iloperidone and 114 haloperidol) were included in the long-term efficacy analysis. The primary efficacy endpoint was time to relapse, defined as an increase in the PANSS-T score of $25 \%$ or more from the start of the long-term phase; discontinuation because of lack of efficacy; aggravated psychosis with hospitalization; or a 2-point or greater increase in the clinical global impression of change (CGI-C) score after week 6. Iloperidone was non-inferior to haloperidol within the stated non-inferiority margin. Rates of relapse differed only slightly between iloperidone (43.5\%) and haloperidol (41.2\%), and reasons for relapse were similar as well. The most common reasons for discontinuation were withdrawal of consent (14.8\% for iloperidone and 8.5\% for haloperidol: number needed to treat (NNT) 16, not significant) and unsatisfactory therapeutic effect (11.1\% and 9.3\%: NNT 56, not significant). Mean time to relapse was 89.8 days for iloperidone (median 50 days) and 101.8 days for haloperidol (median 78 days): however, these differences were not significant.

\section{Efficacy and single nucleotide polymorphisms}

The presence of the null FS63TER allele of the rs 18000169 polymorphism in the gene encoding the ciliary neurotropic factor (CNTF) may potentially increase the risk of schizophrenia. In a four-week randomized, double-blind, placeboand active controlled inpatient study Lavedan and colleagues compared the efficacy of iloperidone $24 \mathrm{mg}$ /day with placebo. Iloperidone was significantly more effective in improving 
PANSS-T, PANSS-P, PANSS-negative (N), BPRS, Clinical Global Impression of Change (CGI-C), and Clinical Global Impression of Severity (CGI-S) scores in schizophrenic inpatients. Iloperidone was significantly more effective than placebo across all measures in patients who were homozygote to $\mathrm{G} / \mathrm{G}$ for $C N T F$ rs $1800169 \mathrm{G} / \mathrm{C}$ polymorphism. Patients with the non-G/G genotype responded similarly to iloperidone and placebo. ${ }^{53}$

More recently, genotypes of 407 patients were analyzed for 334,563 single nucleotide polymorphisms (SNPs). SNPs associated with iloperidone efficacy (based on changes in mean PANSS-T scores) were identified within the neuronal PAS domain protein 3 gene (NPAS3), close to a translocation breakpoint site previously observed in a family with schizophrenia. Five other loci were associated with changes in mean PANSS-T scores after treatment with iloperidone, including the XK, Kell blood group complex subunit-related family, member 4 gene (XKR4), the tenascin-R gene (TNR), the glutamate receptor, inotropic, AMPA 4 gene (GRIA4), the glial cell line-derived neurotrophic factor receptor-alpha2 gene (GFRA2), and the NUDT9P1 pseudogene located in the chromosomal region of the serotonin receptor 7 gene (HTR7). ${ }^{54}$ In the subsequent 28-day inpatients randomized, double-blind, placebo and ziprasidone study application of the six-marker genotype combinations defined four groups of patients with distinct probabilities of response. More than $75 \%$ of iloperidone-treated patients in the group with optimal genotype combinations showed a $20 \%$ or greater improvement, compared with $37 \%$ for patients with other genotypes. The results illustrated the combined use of genetic markers to predict enhanced response to iloperidone, supporting the application of pharmacogenetics to individualize treatments for schizophrenia. ${ }^{55}$

\section{Safety and tolerability Common adverse events}

Iloperidone's safety profile was evaluated in double-blind phase III short-term trials. ${ }^{18,48}$ As mentioned, drugs used as comparators were haloperidol (study 1), risperidone (studies 2 and 3) or ziprasidone, and placebo. Studies 1-3 have been recently reviewed ${ }^{48}$ (see also Table 3 ). The most frequent adverse events (AEs) with iloperidone were dizziness, dry mouth, dyspepsia and somnolence; except for dyspepsia, a relationship with dose was possible. Discontinuation due to AEs was $4.8 \%$ for iloperidone, $7.6 \%$ for haloperidol, $6.2 \%$ for risperidone, and $4.8 \%$ for placebo. ${ }^{48}$ Findings were similar in the ziprasidone-controlled trial in patients with acute exacerbations of schizophrenia. ${ }^{49}$
Although, iloperidone gave lover rates of some particularly troublesome AEs (eg, sedation, somnolence, EPS, akathisia, agitation and restlessness) it had higher rates of tachycardia and orthostatic hypotension than ziprasidone. The rate of orthostatic hypotension was also highest with iloperidone $(19.5 \%)$ in the risperidone-and haloperidol-controlled trials (mostly within the first week of treatment and generally not lasting); no significant changes in blood pressure occurred with haloperidol, risperidone, and placebo. ${ }^{48-50}$ Iloperidone was also associated with higher rates of mean weight gain and the incidence of clinically significant gain was greater than with ziprasidone. Weight increase with iloperidone in this study was slightly higher than the $1.7 \mathrm{~kg}$ increase and $15.2 \%$ rate of clinically significant weight gain after $20-24 \mathrm{mg} /$ day in the risperidone- and haloperidol-controlled trials. ${ }^{48,49}$

Long term safety was checked in the three 52-week trials, in comparison with haloperidol. ${ }^{50}$ Results were consistent with short-term findings; ${ }^{48,49}$ there were no significant differences between week 6 and week 52, with only a slight increase in the rate of patients experiencing at least one AEs with iloperidone, which rose from $68.6 \%$ to $73.3 \%$, and a small decrease with haloperidol, from $79.9 \%$ to $68.6 \%$. Aggravation of schizophrenia and psychosis were the most common serious $\mathrm{AE}$ and were more frequent with iloperidone (18.1\% versus $16.1 \%$ with haloperidol). Most of the weight gain in patients given iloperidone was during the first weeks, after which there were only minimal additional increases. ${ }^{50}$

\section{EPS and akathisia}

In the short-term studies EPS was assessed using the Extrapyramidal Symptom Rating subscale (ESRS). Results have been reviewed elsewhere. ${ }^{48,49}$ Overall rating of EPS in the three six-week, placebo and haloperidol/risperidone-controlled trials indicated improvement from baseline to end-point with all iloperidone doses (4-8, 10-16 and 20-24 mg/day). This was in sharp contrast to haloperidol (15 mg/day), which showed worsening in most of the ESRS subscales. Worsening of akathisia, evaluated using the Barnes Akathisia Scale (BAS), was less frequent with iloperidone than with haloperidol and risperidone (4-8 mg/day) but was not significantly different from placebo (see also Table 3). ${ }^{48}$ In the four-week, placebo and ziprasidone-controlled trial iloperidone (24 mg/day) was not associated with any increase in akathisia, and more patients experienced significant improvement than with placebo. Again, the incidence of EPS was low and not significantly different from placebo, whereas ziprasidone (160 mg/day) was associated with significant worsening in the clinical impression of severity of akathisia. ${ }^{49}$ 
Table 3 Main adverse drug reactions reported in clinical trials

Short term safety trial ${ }^{49}$ (4 weeks)

\begin{tabular}{|c|c|c|c|}
\hline & $\begin{array}{l}\text { Iloperidone } 24 \mathrm{mg} / \text { day } \\
(\mathrm{n}=295)\end{array}$ & $\begin{array}{l}\text { Ziprasidone } 160 \mathrm{mg} / \mathrm{day} \\
(\mathrm{n}=149)\end{array}$ & Placebo $(n=149)$ \\
\hline EPS (\%) & 3 & 9 & 2 \\
\hline Akathisia (\%) & 1 & 7 & 0 \\
\hline \multicolumn{4}{|l|}{ Mean changes from baseline } \\
\hline Orthostatic hypotension (\%) & 7 & 0 & 2 \\
\hline QTc prolongation (msec) & 11.4 & 11.3 & 0 \\
\hline (mean maximum) & 16.2 & 12.3 & -2.4 \\
\hline Weight gain (kg) & 2.8 & I.I & 0.5 \\
\hline Total cholesterol (mg/dL) & 8.1 & 4.1 & -0.5 \\
\hline Triglycerides (mg/dL) & 0.8 & 4.6 & 19.5 \\
\hline Glucose (mg/dL) & 7.9 & 4.7 & 3.2 \\
\hline Prolactin (ng/mL) & 2.6 & 1.9 & -6.3 \\
\hline
\end{tabular}

\begin{tabular}{|c|c|c|c|c|}
\hline & $\begin{array}{l}\text { Iloperidone 4-24 mg/day } \\
(\mathrm{n}=1044)\end{array}$ & $\begin{array}{l}\text { Haloperidol } 15 \mathrm{mg} / \text { day } \\
(\mathrm{n}=1 / 8)\end{array}$ & $\begin{array}{l}\text { Risperidone 4-8 mg/day } \\
(\mathrm{n}=306)\end{array}$ & Placebo $(n=440)$ \\
\hline EPS (\%) & $4-5.4$ & 20.3 & 9.5 & 4.8 \\
\hline Akathisia (\%) & $1.5-4.8$ & 13.6 & 6.9 & 3.6 \\
\hline \multicolumn{5}{|l|}{ Mean changes from baseline } \\
\hline Orthostatic hypotension (\%) & 19.5 & 15.3 & 12.0 & 8.3 \\
\hline QTc prolongation (msec) & $2.9-9.1$ & 5.0 & 0.6 & 0 \\
\hline Weight gain (kg) & $1.5-2.1$ & -0.1 & 1.5 & -0.3 \\
\hline Total cholesterol (mg/dL) & 0.0 & 0.0 & -3.9 & -7.7 \\
\hline Triglycerides (mg/dL) & -26.5 & 0.0 & -26.5 & -35.4 \\
\hline Glucose (mg/dL) & $7.2-16.2$ & 10.8 & 3.6 & -3.6 \\
\hline Prolactin $(\mu g / L)$ & $-38.0 /-23.1$ & 115.8 & 214.5 & -57.4 \\
\hline
\end{tabular}

\begin{tabular}{|c|c|c|}
\hline & Iloperidone 4-16 mg/day $(\mathrm{n}=\mid 23 \mathrm{I})$ & Haloperidol 5-20 mg/day $(n=403)$ \\
\hline EPS (\%) & 0.6 & 7.7 \\
\hline Akathisia (\%) & 3.5 & 18.6 \\
\hline \multicolumn{3}{|l|}{ Mean changes from baseline } \\
\hline Orthostatic hypotension (\%) & NA & NA \\
\hline QTc prolongation (msec) & 3.2 & 4.0 \\
\hline Weight gain (kg) & 2.6 & 0.6 \\
\hline Total cholesterol (mg/dL) & -0.3 & 7.4 \\
\hline Triglycerides (mg/dL) & 0.3 & -0.1 \\
\hline Glucose (mg/dL) & 2.7 & -0.4 \\
\hline Prolactin (ng/mL) & NA & NA \\
\hline \multicolumn{3}{|c|}{ Long-term safety trials ${ }^{50}$ (Data at 52 weeks) } \\
\hline & Iloperidone 4-I6 mg/day $(n=37$ I) & Haloperidol 5-20 mg/day $(\mathrm{n}=1 \mathrm{I} 8)$ \\
\hline EPS (\%) & 0.8 & 5.9 \\
\hline Akathisia (\%) & 3.8 & 14.4 \\
\hline \multicolumn{3}{|l|}{ Mean changes from baseline } \\
\hline Orthostatic hypotension (\%) & NA & NA \\
\hline QTc prolongation (msec) & 10.3 & 9.4 \\
\hline Weight gain (kg) & 3.8 & 2.3 \\
\hline Total cholesterol (mg/dL) & 0.9 & 6.9 \\
\hline Triglycerides (mg/dL) & 6.8 & 12.1 \\
\hline Glucose (mg/dL) & 5.8 & -0.5 \\
\hline Prolactin (ng/mL) & NA & NA \\
\hline
\end{tabular}

Abbreviations: EPS, extrapyramidal symptoms; NA, not available. 
The long-term haloperidol-controlled trial substantiated the favorable safety profile of iloperidone. Overall rating of EPS at the end of the maintenance phase indicated improvement in $48.2 \%$ of patients treated with iloperidone ( 4 to $16 \mathrm{mg} /$ day) compared with $34.7 \%$ of those given haloperidol (5 to $20 \mathrm{mg} /$ day); worsening of symptoms was reported in $13.5 \%$ of patients receiving iloperidone and $36.4 \%$ receiving haloperidol. Akathisia was also worse with haloperidol, being reported in 3.5\% with iloperidone and $18.6 \%$ with haloperidol at week 6 and in $14.4 \%$ and $3.8 \%$ after 52 weeks. The overall rating of akathisia, assessed by the BAS at study end-point, indicated improvement in $24.3 \%$ with iloperidone compared to $16.9 \%$ of patients who received haloperidol. Worsening was noted in respectively $9.2 \%$ and $23.7 \% .^{50}$

\section{QT interval}

The mean changes in corrected QTc intervals using Fridericia's correction were calculated for patients during the short- and long-term trials. In the six-week acute-phase trials the QTc prolongation with iloperidone was doserelated, increasing from 2.9 milliseconds after $4-8 \mathrm{mg}$ to 9.1 milliseconds after 20-24 mg. QTc prolongation averaged respectively 5.0 and 0.6 milliseconds with haloperidol and risperidone. In the ziprasidone-controlled trial the mean prolongation from baseline at study midpoint was 11.4 milliseconds with iloperidone and 11.3 milliseconds with ziprasidone. Mean maximum changes in the QTc interval were similar with iloperidone and ziprasidone, both being significantly greater than with placebo ( -2.4 milliseconds). Two iloperidone-treated and one ziprasidone-treated patient had $\geq 15 \%$ increases in QTc intervals. No patients with a QTc interval $<500$ milliseconds at baseline experienced a change to $\geq 500$ milliseconds. ${ }^{49}$

In the long-term pooled analysis the changes of QTc interval associated to iloperidone were similar to haloperidol: 3.2 milliseconds and 4.0 respectively at week 6 , and 10.3 and 9.4 milliseconds at the end-point. ${ }^{50}$ Importantly, haloperidol as well as risperidone are included in the list of drugs to be avoided for use in patients with diagnosed or suspected congenital long QT syndrome, because of the risk of torsades de pointes (Tdp) (a list of drugs associated with TdP is available at http://www.torsades.org). So, like its comparators, the use of iloperidone might be limited by concern about cardiovascular consequences, requiring careful monitoring of cardiac function.

Interestingly, DNA polymorphisms associated with QTc prolongation have been identified in several loci, including the ceramine kinase-like (CERKL) gene, which is part of the ceramide pathway, involved in the regulation of transmembrane currents. Accordingly, in recent studies, iloperidone- and ziprasidone-treated patients and placebo patients were all genotyped for CERKL protein SNP. Two SNPs within intron 2 of the CERKL gene, rs993648 and rs1441162, were significantly associated with QTc prolongation in iloperidone-patients. At steady-state, patients heterozygous for the rs993648 SNP had a QTc interval of 4.5 milliseconds, whereas patients homozygous for this SNP had a significantly longer QTc interval, 17.8 milliseconds. In ziprasidone-treated patients none of the SNPs showed any correlation with QTc prolongation. The authors concluded that assessing the CERKL gene in patients taking iloperidone could help predict whether they were likely to experience QTc prolongation. ${ }^{56}$

\section{Metabolic side effects}

In the six-week acute-phase trials mild changes in glucose levels were observed in all groups; $7.2 \mathrm{mg} / \mathrm{dL}, 9.0 \mathrm{mg} / \mathrm{dL}$ and $16.2 \mathrm{mg} / \mathrm{dL}$ respectively with iloperidone $4-8 \mathrm{mg} /$ day, $10-16 \mathrm{mg} /$ day and $20-24 \mathrm{mg} /$ day, $3.6 \mathrm{mg} / \mathrm{dL}$ with risperidone and $10.8 \mathrm{mg} / \mathrm{dL}$ with haloperidol. Changes in total cholesterol levels were negligible in all treatment groups. Prolactin content decreased of $38 \mu \mathrm{g} / \mathrm{L}$ and $23.1 \mu \mathrm{g} / \mathrm{L}$ with iloperidone $4-8$ and $10-16 \mathrm{mg} /$ day (results were not available for the $20-24 \mathrm{mg} /$ day dose) but increased with both haloperidol (15 mg/day) and risperidone (4-8 mg/day) (Table 3), which decreased from $38 \mu \mathrm{g} / \mathrm{L}$ and $23.1 \mu \mathrm{g} / \mathrm{L}$ with iloperidone $10-16 \mathrm{mg} /$ day. ${ }^{48}$ Similar findings were observed in the ziprasidone-controlled study, where the incidence of small changes in laboratory parameters was comparable for the active drugs. ${ }^{49}$

Long-term iloperidone also caused slight increases in total cholesterol, triglycerides and glucose, and the change in glucose was higher than with haloperidol; no information was collected about iloperidone's effects of on prolactin. ${ }^{50}$

\section{Special populations}

Information on the pharmacokinetics of iloperidone in children and adolescents, and on its safety and effectiveness compared to adults is lacking. ${ }^{33}$ Information on the pharmacokinetics and pharmacodynamics in the elderly compared to younger healthy subjects is also limited. A phase II randomized, double-blind, placebo-controlled trial evaluated the tolerability and safety of iloperidone $(0.5-6 \mathrm{mg}$ /day in two divided doses) in elderly patients with dementia and psychotic and behavioral disturbances. Iloperidone was well tolerated and safe up to $6 \mathrm{mg} /$ day. ${ }^{36}$ Other studies in elderly patients with psychosis associated with Alzheimer's disease 
suggested there may be different tolerability profiles in this population and younger patients with schizophrenia. ${ }^{33}$

Renal impairment does not significantly change iloperidone pharmacokinetics after single dose $(3 \mathrm{mg})$, reflecting its extensive hepatic metabolism (less than $1 \%$ of the drug is excreted unchanged). Mean maximum plasma concentrations of its main metabolites too were only minimally affected by renal impairment (creatinine clearance $<30 \mathrm{~mL} / \mathrm{min}$ ) after a $3 \mathrm{mg}$ single dose; mean AUC was reduced by only $6 \%$ for reduced iloperidone and increased by $52 \%$ for the inactive P95-1213 compared to healthy subjects. ${ }^{33,34}$

The effects of hepatic impairment on iloperidone pharmacokinetics are not yet clear, ${ }^{34}$ but a recent abstract suggested that exposure to the active reduced iloperidone markedly increased in mild or moderate hepatic-impaired patients compared with matched healthy subjects after a single iloperidone dose ( $2 \mathrm{mg}$ ). Iloperidone should therefore not be given to people with mild, moderate or severe hepatic impairment, especially if a CYP2D6 deficiency is suspected or drugs that inhibit CYP2D6 or induce or inhibit CYP3A are added to or subtracted from iloperidone. ${ }^{33}$

As mentioned, PM of CYP2D6 have higher exposure to iloperidone and its main metabolites compared with EM subjects, ${ }^{33}$ it is about $47 \%$ higher for the parent drug, $85 \%$ for the reduced metabolite and $85 \%$ for the inactive metabolite. ${ }^{34}$ Aripiprazole, rioperidone and sertindole too present polymorphic metabolism characteristics mirroring the CYP2D6 phenotype, ${ }^{21,57}$ although for risperidone the concentrations of the active fraction (parent drug + active metabolite) varied little between EM and PM at CYP2D6. ${ }^{43}$

Interestingly, recent studies not yet published in full have identified variant CYP2D6 genotypes that result in higherthan-normal exposure to iloperidone. These have investigated the association between the CYP2D6 $1846 \mathrm{G}>\mathrm{A}$ polymorphism, which is associated with the CYP2D6*4 allele and includes the GG (wild-type), AA, AG, and GA genotypes, and the degree of QTc interval prolongation. The study drew on 74 patients enrolled in an open-label safety study of iloperidone and classified them as normal (GG), intermediate (AG) and poor metabolizers (AA) of this drug, based on the plasma iloperidone-to-metabolite concentration ratios (iloperidone + active metabolite/inactive metabolite). Exposure to the active drug was greater in patients with the AA genotype. After 14 days of iloperidone treatment, the QTc prolongation in intermediate/poor metabolizers (AG/AA) was 15 milliseconds compared to 10.4 milliseconds in GG patients $(P=0.008)$. Patients with either genotype showed adaptation with continued treatment and after 28 days the
QTc prolongation was 12.9 milliseconds and 5 milliseconds in AG/AA and GG patients. Thus at steady state iloperidone CYP2D6 polymorphism was associated with exposure to the drug, and this correlated with different metabolic ratios that result in different QTc prolongation. ${ }^{58}$

As mentioned, other pharmacogenetic studies of iloperidone have also identified biomarkers that may assist clinicians in predicting treatment response and AE. These have provided new information on efficacy and adverse reactions to iloperidone, with the goal of predicting which patients are likely to have the best benefit-to-risk ratio QTc ratio for prolongation after iloperidone (for reviews $\mathrm{see}^{31,59}$ ).

\section{Conclusions}

Like other second-generation antipsychotics, iloperidone has high affinity for $5-\mathrm{HT}_{2 \mathrm{~A}}$ receptors and $\alpha_{1}$ adrenergic receptors and moderate affinity for $\mathrm{D}_{2}$ receptors and is recommended for the acute treatment of adult schizophrenic patients. Based on efficacy studies the recommended starting dose was $1 \mathrm{mg}$ b.i.d, which can be titrated by daily increases to $12-24 \mathrm{mg}$ /day up to the recommended target dose, although the optimal duration of therapy remains to be established. Doses should be halved for concomitant administration with strong CYP2D6 and CYP3A4 inhibitors. Similarly, PM of CYP2D6 have higher exposure to iloperidone than EM subjects, and dosing adjustment is needed. Iloperidone's efficacy was also assessed in relation to specific genetic profiling. Preliminary data suggest that several putative SNPs may be associated with an enhanced response to iloperidone although further studies are needed before these polymorphisms can be used to individualize iloperidone treatment schedule.

As reviewed elsewhere, ${ }^{31,38}$ a pharmacodynamicpharmacokinetic correlation was tentatively established for this drug, with the minimal effective concentration appearing to be $5 \mathrm{ng} / \mathrm{mL}$ in patients with schizophrenia. However, iloperidone is extensively metabolized to reduced iloperidone and the metabolite-to-parent drug ratio varies with endogenous and exogenous factors affecting the patient's metabolic status, this probably being the main source of iloperidone pharmacokinetic variability within and between populations.

Information on the efficacy and safety of iloperidone in potentially at-risk populations such as children and adolescents, elderly patients, and subjects with impaired organ function is still limited or lacking.

Although iloperidone was effective and generally well tolerated in several controlled short and longer trials - showing greater efficacy than placebo and indirectly comparable to either first- or second-generation drugs on positive and 
negative symptoms of schizophrenia - these enrolled only small numbers of highly selected patients, with a non-inferiority design, and lacking any direct "head-to-head" comparison with other second-generation antipsychotic agents. The studies comparing iloperidone with risperidone and ziprasidone were not designed to test these different antipsychotics directly. These weaknesses limit the general extension of the results to patients with other psychological or clinical comorbidities, those with comorbid drug use and/or dependence, those resistant to treatment with other antipsychotics, and adolescents or elderly patients. Moreover, data are limited on iloperidone's effectiveness in the maintenance treatment of schizophrenia. The only available data demonstrated non-inferiority to haloperidol in a subsample of responsive patients. Lacking direct comparative data, it is difficult to define the place in therapy of this new agent in the treatment of schizophrenia. Lack of direct comparative assessment, slow initial titration, twicedaily administration, and cost are all significant obstacles to considering iloperidone for first-line therapy in schizophrenia. Further well designed comparative studies are now needed to clarify the therapeutic role and advantages of the new antipsychotic agent in terms of efficacy and safety.

Although iloperidone appears to have a favorable safety profile as regards to the minimal EPS and metabolic syndrome observed in clinical trials, the effect on the QT interval is of concern. Prolongation of QT interval is comparable to that with ziprasidone, which was not licensed in the UK because of concerns about potential cardiotoxicity. QT interval prolongation is the best available predictor for TdP episodes and is considered a risk factor for sudden cardiac death. A rising number of structurally unrelated and non-cardiovascular drugs prolong the QT interval and this is the most common cause of withdrawal or restriction of the use of drugs on the market. ${ }^{60,61}$ Drugs that may cause TdP at therapeutic dosages, such as sotalol, dofetilide or ibutile, can prolong the QT interval by more than 50 milliseconds, while the maximum prolongation of QT interval with iloperidone is considerably less (16.2 milliseconds). However, iloperidone, like any new drug, has been tested only in small samples of patients and the risk of TdP in the general population remains unknown. This risk is in fact associated to the risk of drug interaction and to the number and characteristics of patients exposed to the treatment in clinical practice. A small increase in the QT interval can lead to fatal arrhythmias.

Before prescribing iloperidone therefore clinicians must consider risk factors for drug-induced TdP including female sex, cardiac hypertrophy, heart failure, bradycardia, electrolyte imbalances (hypokalemia, hypocalcemia), congenital QT syndrome and pharmacodynamic and pharmacokinetic drug interactions. As mentioned, the effect on the QT interval is amplified by inhibition of iloperidone metabolism and polymorphism of CYP2D6 could further affect its metabolism increasing the risk of TdP. So several factors must be considered in order to avoid cardiac events and to personalize medicine in schizophrenic patients according to specific genotypes. Finally, the role of post-marketing surveillance is important and should monitor iloperidone for arrhythmias or TdP, identifying any early warning signs.

The clinical advantages of the new antipsychotic agents are not well evaluated by direct superiority comparative studies. The lack of such evidence adds to the difficulty of establishing the place in therapy of iloperidone and the other new agents, and providing clinicians with clear indications to guide the choice of the best treatment for each schizophrenic patient. Well designed, and appropriately powered clinical and pharmacogenetic studies are now needed to clinically assess the therapeutic role of iloperidone in schizophrenia.

\section{Disclosures}

The authors have no conflicts of interest to disclose.

\section{References}

1. Saha S, Chant D, Welham J, Mgrath J. A systematic review of the prevalence of schizophrenia. PLoS Med. 2005;2(5):e141.

2. Stahl SM. Symptoms and circuits, part 3: schizophrenia. J Clin Psychiatry. 2004;65:8-9.

3. Seeman MV. Symptoms of schizophrenia: normal adaptations to inability. Med Hypotheses. 2007;69:253-257.

4. Wu EQ, Birnbaum HG, Shi L, et al. The economic burden of schizophrenia in the United States in 2002. J Clin Psychiatry. 2005;66:1122-1129.

5. Salize HJ, McCabe R, Bullenkamp J, et al. Cost of treatment of schizophrenia in six European countries. Schizophr Res. 2009;1 11(1-3):70-77.

6. Rössler W, Salize HJ, van Os J, Riecher-Rössler A. Size of burden of schizophrenia and psychotic disorders. Eur Neuropsychopharmacol. 2005;15(4):399-409.

7. Bondy B, Spellmann I. Pharmacogenetics of antipsychotics: useful for the clinician? Curr Opin Psychiatry. 2007;20(2):126-130.

8. Lieberman JA, Stroup TS, McEvoy JP, et al; Clinical Antipsychotic Trials of Intervention Effectiveness (CATIE) Investigators. Effectiveness of antipsychotic drugs in patients with chronic schizophrenia. $N$ Engl J Med. 2005;353:1209-1223.

9. Seeman P, Lee T, Chau-Wong M, Wong K. Antipsychotic drug doses and neuroleptic/dopamine receptors. Nature. 1976;261(5562):717-719.

10. Di Forti M, Lappin JM, Murray RM. Risk factors for schizophreniaall roads lead to dopamine. Eur Neuropsychopharmacol. 2007; 17 Suppl 2:S101-S107.

11. Emsley RA. Partial response to antipsychotic treatment: the patient with enduring symptoms. J Clin Psychiatry. 1999;60 Suppl 23:10-13.

12. Luft B, Taylor D. A review of atypical antipsychotic drugs versus conventional medication in schizophrenia. Expert Opin Pharmacother. 2006; 7(13):1739-1748.

13. Tarsy D, Baldessarini RJ. Epidemiology of tardive dyskinesia: is risk declining with modern antipsychotics? Mov Disord. 2006;21(5): 589-598. 
14. Haddad PM, Wieck A. Antipsychotic-induced hyperprolactinaemia: mechanisms, clinical features andmanagement. Drugs. 2004;64(20): 2291-2314.

15. Meltzer HY. The role of serotonin in antipsychotic drug action. Neuropsychopharmacology. 1999;21(2):106S-115S.

16. Luft B, Taylor D. A review of atypical antipsychotic drugs versus conventional medication in schizophrenia. Expert Opin Pharmacother. 2006;7(13):1739-1748.

17. Bishara D, Taylor D. Upcoming agents for the treatment of schizophrenia: mechanism of action, efficacy and tolerability. Drugs. 2008;68(16):2269-2292.

18. Potkin SG. New advances in the treatment of schizophrenia. Introduction. J Clin Psychopharmacol. 2008;28(2 Suppl 1) $\mathrm{S} 1-\mathrm{S} 3$.

19. Citrome L. Iloperidone for schizophrenia: a review of the efficacy and safety profile for this newly commercialised second-generation antipsychotic. Int J Clin Pract. 2009;63(8):1237-1248.

20. Strupczewski JT, Bordeau KJ, Chang Y, et al. 3-[[(Aryloxy)alkyl]pi peridinyl]-1,2-benzisoxazoles as $\mathrm{D}_{2} / 5-\mathrm{HT}_{2}$ antagonists with potential atypical antipsychotic activity: antipsychotic profile of iloperidone (HP 873). J Med Chem. 1985;28(6):761-769.

21. Caccia S. Biotransformation of post-clozapine antipsychotics: pharmacological implications. Clin Pharmacokinet. 2000;38(5): 393-414

22. Kongsamut S, Roehr JE, Cai J, et al. Iloperidone binding to human and rat dopamine and 5-HT receptors. Eur J Pharmacol. 1996;317: 417-423.

23. Kalkman HO, Subramanian N, Hoyer D. Extended radioligand binding profile of iloperidone: A broad spectrum dopamine/serotonin/ norepinephrine receptor antagonist for the management of psychotic disorders. Neuropsychopharmacology. 2001;25:904-914.

24. Richelson E, Souder T. Binding of antipsychotic drugs to human brain receptors: Focus on newer generation compounds. Life Sci. 2000;68:29-39.

25. Kalkman HO, Feuerbach D, Lotscher E, Schoeffter P. Functional characterization of the novel antipsychotic iloperidone at human $\mathrm{D}_{2}, \mathrm{D}_{3}$, alpha ${ }_{2 \mathrm{C}}, 5-\mathrm{HT}_{6}$, and 5-HT ${ }_{1 \mathrm{~A}}$ receptors. Life Sci. 2003;73: 1151-1159.

26. Parsons B, Allison DB, Loebel A, et al. Weight effects associated with antipsychotics: a comprehensive database analysis. Schizophr Res. 2009;110(1-3):103-110.

27. Szewczak MR, Corbett R, Rush DK, et al. The pharmacological profile of iloperidone, a novel atypical antipsychotic agent. J Pharmacol Exp Ther. 1995;274(3):1404-1413.

28. Barr AM, Powell SB, Markou A, Geyer MA. Iloperidone reduces sensorimotor gating deficits in pharmacological models, but not a developmental model, of disrupted prepulse inhibition in rats. Neuropharmacology. 2006;51(3):457-465.

29. Corbett R, Hartman H, Kerman LL, et al. Effects of atypical antipsychotic agents on social behavior in rodents. Pharmacol Biochem Behav. 1993;45(1):9-17.

30. Hesselink JM. Iloperidone (Hoechst Marion Roussel Inc). IDrugs. 1999;2(6):584-590.

31. Nnadi CU, Malhotra AK. Clinical and pharmacogenetic studies of iloperidone. Personalized Medicine. 2008;5(4):367-375.

32. Gemperle AY, McAllister KH, Olpe HR. Differential effects of iloperidone, clozapine, and haloperidol on working memory of rats in the delayed non-matching-to-position paradigm. Psychopharmacology (Berl). 2003;169(3-4):354-364.

33. Fanapt (iloperidone tablets). Drug information http://www.rxlist.com/ fanapt-drug.htm (accessed September 2009).

34. US Food and Drug Administration. Iloperidone, Approval Hystory, NDA 022192, review: (accessed September 2009).

35. Sainati SM, Hubbard JW, Chi E, et al. Safety, tolerability, and effect of food on the pharmacokinetics of iloperidone (HP 873), a potential atypical antipsychotic. J Clin Pharmacol. 1995 Jul;35(7):713-720. Erratum in: J Clin Pharmacol. 1996;36(1):92.
36. Jain KK. An assessment of iloperidone for the treatment of schizophrenia. Expert Opin Investig Drugs. 2000;9(12):2935-2943.

37. Wang JS, Ruan Y, Taylor RM, et al. The brain entry of risperidone and 9-hydroxyrisperidone is greatly limited by P-glycoprotein. Int $J$ Neuropsychopharmacol. 2004;7(4):415-419.

38. Albers LJ, Musenga A, Raggi MA. Iloperidone: a new benzisoxazole atypical antipsychotic drug. Is it novel enough to impact the crowded atypical antipsychotic market? Expert Opin Investig Drugs. 2008;17(1):61-75.

39. Vermeir M, Naessens I, Remmerie B, et al. Absorption, metabolism, and excretion of paliperidone, a new monoaminergic antagonist, in humans. Drug Metab Dispos. 2008;36(4):769-779.

40. Mutlib AE, Strupczewski JT, Chesson SM. Application of hyphenated $\mathrm{LC} / \mathrm{NMR}$ and LC/MS techniques in rapid identification of in vitro and in vivo metabolites of iloperidone. Drug Metab Dispos. 1995;23(9): 951-964.

41. Mutlib AE, Klein JT. Application of liquid chromatography/mass spectrometry in accelerating the identification of human liver cytochrome P450 isoforms involved in the metabolism of iloperidone. J Pharmacol Exp Ther. 1998;286:1285-1293.

42. Subramanian N, Kalkman HO. Receptor profile of P88-8991 and P95-12113, metabolites of the novel antipsychotic iloperidone. Prog Neuropsychopharmacol Biol Psychiatry. 2002;26(3):553-560.

43. DeVane CL, Nemeroff CB. An evaluation of risperidone drug interactions. J Clin Psychopharmacol. 2001;21(4):408-416.

44. Corbett R, Griffiths L, Shipley JE, et al. Iloperidone: preclinical profile and early clinical evaluation. CNS Drug Rev. 1997;3:120-147.

45. Borison RL, Huff FJ, Griffiths L. Efficacy of $4 \mathrm{mg} /$ day and $8 \mathrm{mg}$ iloperidone administered to schizophrenic patients for 42 days. Psychopharmacol Bull. 1996;32:416.

46. Mucke HA, Castaner J. Iloperidone. Drug Future. 2000;25:29-40.

47. Potkin SG, Litman RE, Torres R, Wolfgang CD. Efficacy of iloperidone in the treatment of schizophrenia: initial phase 3 studies. J Clin Psychopharmacol. 2008;28(2 Suppl1):S4-S11.

48. Weiden PJ, Cutler AJ, Polymeropoulos MH, et al. Safety profile of iloperidone: a pooled analysis of 6-week acutephase pivotal trials. J Clin Psychopharmacol. 2008;28(2 Suppl 1):S12-S19

49. Cutler AJ, Kalali AH, Weiden PJ, et al. Four week, double-blind, placebo- and ziprasidone-controlled trial of iloperidone in patients with acute exacerbation of schizophrenia. J Clin Psychopharmacol. 2008; 28(2 Suppl 1):S20-S28.

50. Kane JM, Lauriello J, Laska E, et al. Long-term efficacy and safety of iloperidone: results from 3 clinical trials for the treatment of schizophrenia. J Clin Psychipharmacol. 2008;28(2 Suppl 1):S29-S35.

51. Hamilton J, Wolfang CD, Feeney J, Polymeropulos MH. Efficacy of iloperidone is comparable to risperidone in analyses of a placeboand risperidone-controlled clinical trial for schizophrenia. (poster no. NR1-033) 162nd Annual Meeting of the American Psychiatric Association 2009 May 16-21; San Francisco (CA) USA.

52. Feeney J, Wolfang CD, Polymeropulos MH. The comparative efficacy of iloperidone and haloperidol across four short-term controlled trials. (poster no. NR1-026) 162nd Annual Meeting of the American Psychiatric Association 2009 May 16-21; San Francisco (CA) USA.

53. Lavedan C, Volpi S, Polymeropulos MH, Wolfang CD. Effect of ciliary neurotrophic factor polymorphism on schizophrenia symptom improvement in an iloperidone clinical trial. Pharmacogenomics. 2008; 9:289-301.

54. Lavedan C, Licamele L, Volpi S, et al. Association of the NPAS3 gene and five other loci with response to the antipsychotic iloperidone identified in a whole genome association study. Mol Psychiatry. 2009; 14:804-819.

55. Volpi S, Potkin SG, Malhotra AK, et al. Applicability of a genetic signature for enhanced iloperidone efficacy in the treatment of schizophrenia. J Clin Psychiatry. 2009;70(6):801-809.

56. Volpi S, Heaton C, Mack K, et al. Whole genome association study identifies polymorphisms associated with QT prolongation during iloperidone treatment of schizophrenia. Mol Psychiatry. 2009;14(11): 1024-1031. 
57. Spina E, de Leon J. Metabolic drug interactions with newer antipsychotics: a comparative review. Basic Clin Pharmacol Toxicol. 2007;100(1):4-22.

58. Wolfgang CD, Polymeropoulos MH. Single-nucleotide polymorphisms in the CYP2D6 gene are correlated with iloperidone drug exposure levels, impacting the degree of $\mathrm{QT}_{\mathrm{c}}$ prolongation associated with iloperidone treatment [abstract]. Presented at: the 57th Annual Meeting of the American Society of Human Genetics; 2007, October 23-27; San Diego, CA. Abstract 1040/T.
59. Scott LJ. Iloperidone: in schizophrenia. CNS Drugs. 2009;23(10): $867-880$.

60. Roden DM. Drug induced prolongation of the QT interval. Druginduced prolongation of the QT interval. N Engl J Med. 2004;350(10): 1013-1022.

61. Letsas KP, Efremidis M, Kounas SP, et al. Clinical characteristics of patients with drug-induced QT interval prolongation and torsades de pointes: identification of risk factors. Clin Res Cardiol. 2009;98: 208-212.

\section{Publish your work in this journal}

Drug Design, Development and Therapy is an international, peerreviewed open-access journal that spans the spectrum of drug design and development through to clinical applications. Clinical outcomes, patient safety, and programs for the development and effective, safe, and sustained use of medicines are a feature of the journal, which has also been accepted for indexing on PubMed Central. The manuscript management system is completely online and includes a very quick and fair peer-review system, which is all easy to use. Visit http://www.dovepress.com/testimonials.php to read real quotes from published authors.

\footnotetext{
Submit your manuscript here: http://www.dovepress.com/drug-design-development-and-therapy-journal
} 